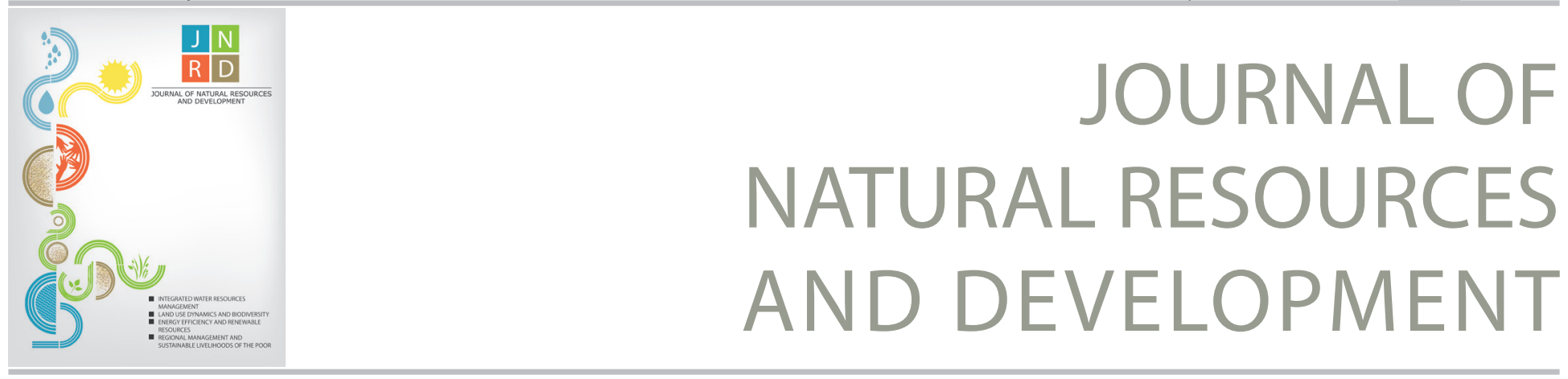

Research article

\title{
Assessing How Collaborative Resource Management Impacts Victims' Perspectives on Wildlife Crop Raids
}

\author{
Nana Owusu-Ansah ${ }^{\text {* }}$ \\ ${ }^{a}$ Wildlife Division of the Forestry Commission of Ghana, P. O. Box M239 Accra-Ghana \\ * Corresponding author: naduono74@yahoo.co.uk
}

\section{Article history}

Received

Accepted

$05 / 05 / 2018$

Published 01/11/2018

\section{Keywords}

Development

Conflict

Conservation

Retaliation

Species

Sustainability

\section{Abstract}

Collaborative resource management has been touted as one of the ways conservation of wildlife resources can be improved, especially in off-protected areas. Three indicators were used to test whether collaboration between the Wildlife Division of the Forestry Commission of Ghana and local communities has any impact on farmers' perspectives on crop raiding. The indicators were: (1) methods used by farmers to reduce raiding, (2) institutions to which farmers report raids, and (3) the kind of assistance needed to reduce raiding. The findings suggest there were no differences between the collaborative indicators and the two chosen study locations. However, on the question of institutions where raiding incidences were reported and location, the difference was significant $\left(X^{2}=14.523 ; D \circ F=5\right.$; $\mathrm{P}=0.01261$ ). In addition, there was a statistically significant relation between location and participants' responses to species that raided their crops $\left(X^{2}=16.988\right.$; DoF $\left.=4 ; p=1.943 e-3\right)$. Participants from the two locations did not show differences in their responses to preventive methods. Male respondents mentioned the use of traps as their major preventive method, although this is against wildlife hunting regulations in Ghana. Educating and supporting farmers with appropriate preventive methods that reduce their losses to wildlife crop raiding is recommended to improve conservation.

(c) 2018 This is an open access article under the CC BY-NC-ND license (http://creativecommons.org/licenses/bync-nd/4.0/).

\section{Introduction}

An increasing global human population with its quest to produce food through expansive agriculture [1] is inching into pristine ecosystems. This phenomenon has increased the incidences of human-wildlife conflicts [2], [3], especially in areas where wildlife conservation is in focus. The negative impacts of wild life conservation conflict on other forms of land use are costly and destructive [2]. The conflict prevents 
effective conservation as it creates inequality and hampers socioeconomic development which in turn affects sustainability.

The destructive cost to wildlife conservation of ineffective management of conservation conflicts promotes retaliatory killing of key species which are also the drivers of revenue receipts through eco-tourism that in turn funds conservation [2]. It has been reported that farmers kill wildlife in retaliation when they suffer crop raids [4], [5], [6]. This brings into focus the need to bridge the conservationists' stances and those of socio-economic developers. Conservation and development practitioners have been urged not to see themselves as advocates of two opposing disciplines but rather two ends of a bridge [7].

Crossing to either end requires conservation and development strategists to meet each other half way. The goal for such development and conservation programs is to reduce the conflict and dichotomy between conservation and socio-economic development [7]. According to [2], the conservationists and the socio-economic developers should have shared solutions that are developed from compromises that promote win-win situations or at worst avoid total losses to any of the parties.

\subsection{Collaborative Resource Management}

Conservation management in Ghana and other countries has moved from strict governmental control to collaborative resource management [8], [9] and [10]. The policy shift aims to reduce the negative impacts of conservation such as wildlife crop raids on food security and the socio-economic living standards of farmers who bear the brunt of crop raids. The new mix of centralized governmental control and community collaborative resource conservation management aims to promote both conservation and socio-economic development [11], [12]. Indeed, many foreign socioeconomic development assistance programs from development partners have been designed with natural resources conservation components [13], [14].

In Ghana, there are basically two types of collaborative arrangements for wildlife conservation [15]. The first model is where the Wildlife Division (WD) of the Forestry Commission of Ghana devolves authority to local communities in areas endowed with wildlife resources to enforce their own bylaws for the benefit of the communities. This partnership rests on the concept of Community-Based Natural Resource Management (CBNRM) [10] which in Ghana has led to socalled Community Resource Management Areas (CREMAs) [8], [15]. Under this model, except with regard to wildlife species categorized as first schedule [16], managers of these CREMAs have the authority that has been devolved from the WD to utilize wildlife resources according to their approved management plan [17]. CREMAs have the autonomy to utilize wildlife species found within their area under an agreed constitution, bylaws and a management plan which also defines benefit sharing to members.

The second type of collaborative resource management occurs within communities that fringe protected areas. Under this model conservation managers engage communities to assist them in managing the protected area. Natural resource management committees known as Community Resource Management Committees (CRMCs) are set up to help protected area managers work effectively [17]. In protected areas where this concept is fully developed, the various committees within one political district form what is called a Protected Area Management Advisory Unit (PAMAU) and if the protected area falls in more than one political district, the PAMAUs aggregate to form a Protected Area Management Board (PAMAB). These bodies are not autonomous as in the first model, but they work in concert with the protected area management [15]. This arrangement is not mandatory for protected area managers to set up but rather depends on the demands of the time, such as availability of funding and the level of cooperation among the different stakeholders. Again, fringe communities of protected areas can also form CREMAs as in the first model, even if the second type of arrangement exists.

These two arrangements clearly present different perspectives for stakeholders. For example, it is reported that community members under the first model where authority is devolved have the right attitude towards conservation and this can be inferred to impact positively on how conservation conflicts are managed [18], [8], [7] and [19]. The devolution of authority creates a sense of ownership for the resources among participating communities. In the second arrangement community members have no resource use rights unless a permit has been granted by the centralized authority and this could limit participation [20].

\subsection{Conceptual Framework for the Study}

This study is designed based on the framework developed by [20], as shown in Figure 1 below.

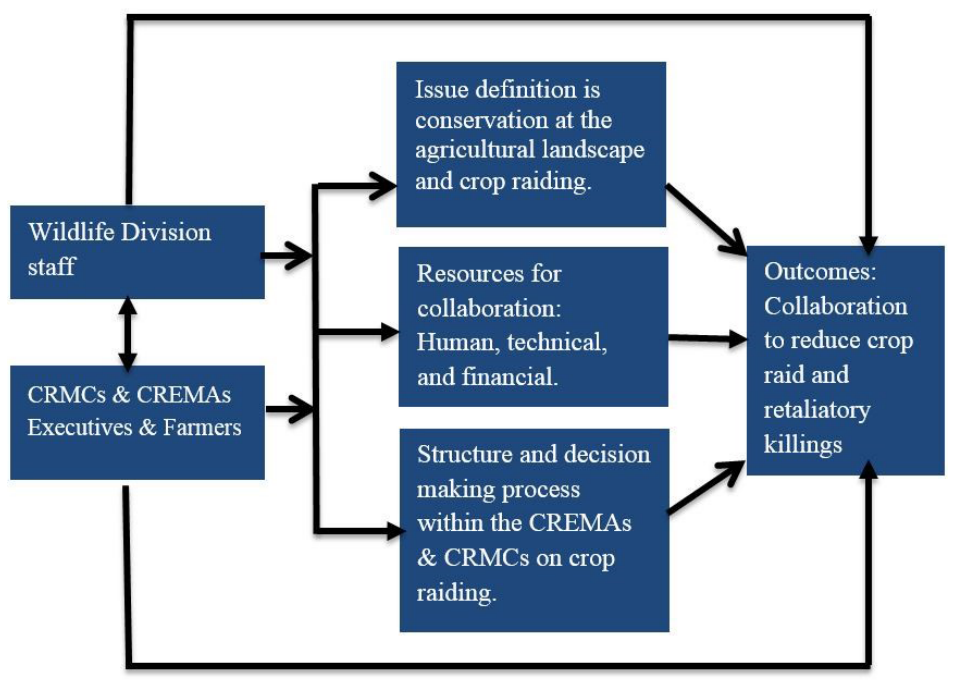

Figure 1: Framework for analyzing governmental impacts on collaborative environmental management. Adapted from [20]. 
Koontz [20] states that government, as an institution and as an actor, has an impact on the kind of collaborative environmental management that exists in a country. Inferring from the framework for assessing government impacts on collaboration outcomes [20], the actors (WD staff) are the people with the skills, beliefs, values and attitudes that shape the institution they manage and thus impact the kind of collaboration that is developed between them and the CRMCs and CREMAs. Again, government as an institution created the WD to develop rules, regulations, laws, and structures for wildlife conservation management in Ghana. How issues of wildlife crop raiding are viewed by victims (farmers) in the agricultural landscape is contingent on the collaborative relationship they have with the WD [2]. This means that the available human, technical and financial resources of the WD impact on the decision-making processes of the victims in managing crop raiding by wildlife. A positive outcome of farmers not resorting to retaliatory killing [4], [6] will depend on measures that mitigate their loss and improve their socio-economic circumstances.

This paper aims to answer the following research question: Does collaboration have an impact on the perspectives of farmers who suffer crop raids? The purpose is to understand whether the two models of collaboration impact differently on victims of crop raids. Three aspects of crop raid management were used as indicators to understand the collaborative perspectives of the victims. The indicators are 1) methods used to reduce raiding, 2) institutions that receive raiding reports, and 3) the kind of assistance needed to reduce raiding. The assumptions are that a positive collaborative relationship will lead farmers to adopt methods that are acceptable to the WD to prevent crop raiding. Farmers were also expected to report to the WD and its agents (CREMA and the CRMCs executives) for assistance when crops are raided, and lastly farmers' requests for support will depend on how the WD can assist them to prevent crop raiding, thus preventing them from turning to retaliatory killings. The purpose is to improve collaboration between protected area managers and communities ([8], [10] and [8]) and to reduce retaliatory killing [4], [6] of wildlife while improving the food security of farmers.

\section{Research Methods}

\subsection{Material and methods}

This study was carried out in six communities that fringe the Gbele Resource Reserve (GRR), which uses the CRMCs collaboration model, and within the Sayinga-Kasena-Gavara-Kara (SKGK), which uses the CREMA model. Geographically GRR is situated between latitudes $10^{\circ}$ $22^{\prime} 35^{\prime \prime}$ and $10^{\circ} 44^{\prime} 40^{\prime \prime} \mathrm{N}$ and longitudes $2^{\circ} 03^{\prime} 12^{\prime \prime}$ and $2^{\circ} 12^{\prime} 34^{\prime \prime} \mathrm{W}$, with a total land area of $565 \mathrm{~km}^{2}$. The SKGK lies between latitudes $10^{\circ} 45^{\prime} 45^{\prime \prime} \mathrm{N}$ and $11^{\circ} 00^{\prime} 12^{\prime \prime} \mathrm{N}$ and longitudes $1^{\circ} 18^{\prime} 00^{\prime \prime} \mathrm{W}$ and $1^{\circ} 39^{\prime}$ $00^{\prime \prime} \mathrm{W}$ and covers $587.26 \mathrm{~km}^{2}$ [17]. See Figure 2 for study locations in northern Ghana.

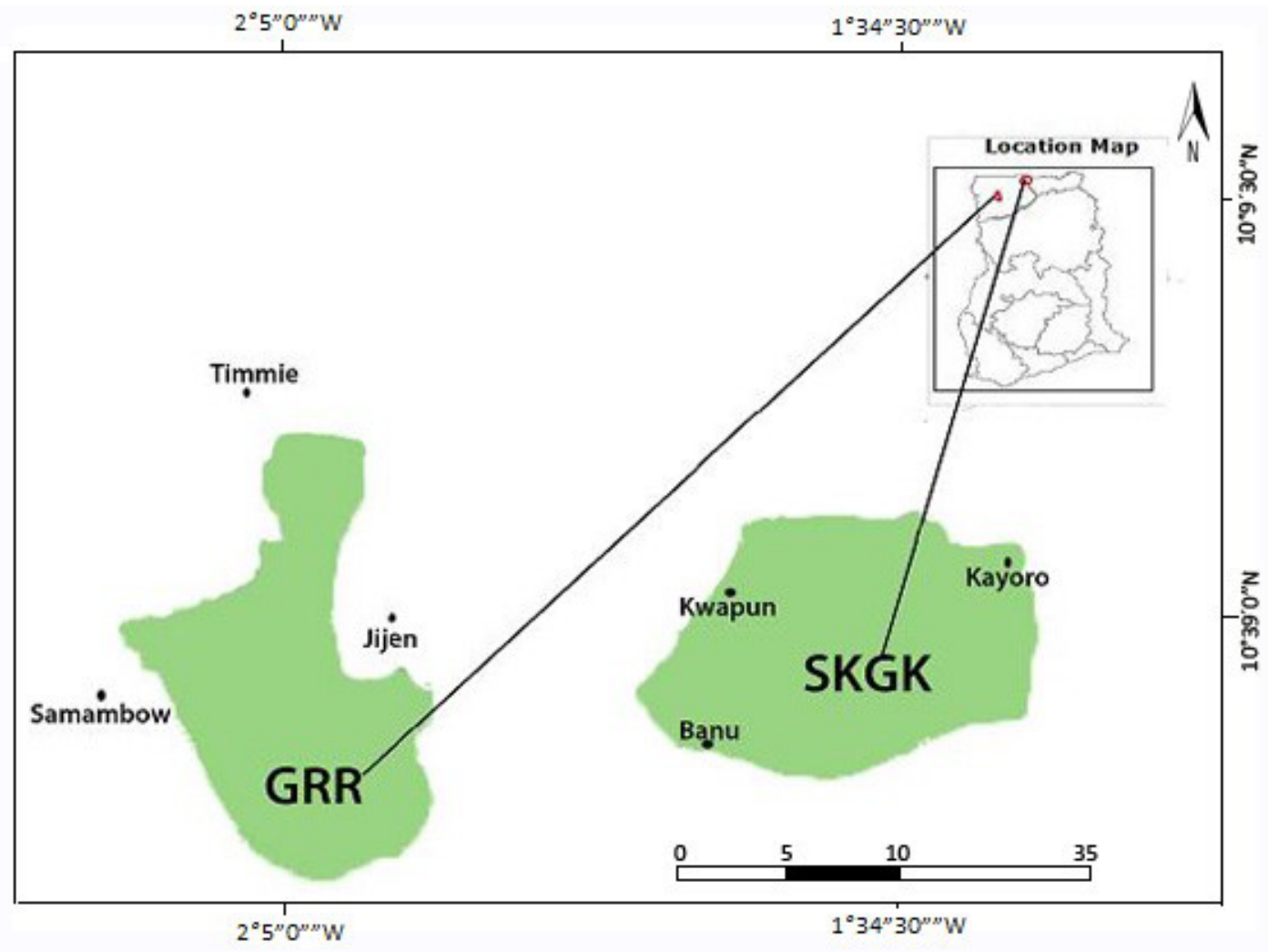

Figure 2: Map showing the two study sites. Source: The Wildlife Division [17]. 
Three communities were selected within each of the two study sites for data collection. In the GRR the communities were Timmie, Samanbow and Jijen and in the SKGK they were Kwapun, Banu and Kayoro. The communities were purposely selected based upon their proximity to the GRR boundary line or the core zone of the SKGK as well as to reflect the political districts where they are located. Banu and Kwapun fall within the Sissila East Municipality of the Upper West Region, while Kayoro is in the Kasena Nakana West District of the Upper East Region. All the GRR communities are in the Upper West Region with Jijen located in the Sissila East Municipality, Timmie is in the Sissila West District and Samanbow is in the Daffiama-Issa-Busie District. The approximate distances of GRR communities to the PA boundary line ranges between seven to ten kilometers and those of the SKGK are between five to seven kilometers. The assumption was that the closer the community is to the protected areas the higher the possibility of the farmers' crops suffering raids.

The study sites are within the Guinea Savannah ecological zones [21] in the Upper-West and Upper-East Regions of Ghana. The area has a single modal rainy season which starts in May and ends in October. The crops cultivated in these areas are mainly cereals (maize, sorghum, millet) and legumes (soya, groundnut and cowpea). However, crops like yam and cotton are also cultivated. The area is also known to be rich in biodiversity [22] with species like the Elephant (Loxodonta africana) and the Roan Antelope (Hippotragus equines), while primate species like the Patas Monkey (Erythrocebus patas), Baboon (Papio anubis), Green Monkey (Cercopithecus aethiops) and both resident and migrant birds have been recorded [23].

\subsection{Data collection}

Data was collected through semi-structured interviews. The participants in the study were mainly farmers. In each of the six communities, the biggest farmer group was purposively selected through a snowballing technique [24], [25] by contacting the community chief to nominate the largest farmer group in the community. The members of the nominated biggest farmer group who were available were interviewed separately. Data collection took two months to complete from June to August 2017 in the period farmers had finished planting their crops. Data collection was done early in the morning of each agreed date with the farmer groups to enable them to go back to their farms or to do other activities for the day. Eighty-six individuals took part in the study. 46 were from the SKGK and 40 were from the GRR. Participants were assured of the confidentiality of any sensitive information linking them to the publication.

The study results are presented in tables and charts. The data analysis was done to determine whether participants' perspective is impacted by the collaboration efforts of the WD in their communities. A chisquared statistical analysis was done to determine the differences in participants' perspectives in relation to the collaboration models of CRMC in the GRR and CREMA in the SKGK. The chi-squared test was appropriate in determining the statistical differences of the categorical data collected from the two study locations. Data analysis was done with the assistance of Statistics Open for All (SOFA) software version 1.4.6.

\section{Results and Discussion}

\subsection{Participant demographics}

A total of 86 participants from six farmer groups took part in the study and gave responses to interview questions. Forty-six were from the SKGK and 40 were from the GRR. Participants to this study were all farmers and were reported to have experienced wildlife crop raiding within the past five years. Therefore, the participants and their communities constitute typical cases [26] within the subject under study. Males formed the majority of participants with $69.7 \%$, while $30.3 \%$ of participants were female. The SKGK had two more female and four more male participants than the GRR.

Table 1 below shows the mean distances to farms and mean farm sizes divided up by participants' age groups and gender. The table also shows the standard deviation and range figures of age groups, farm distances and farm sizes. Mean farm distances from the participants' communities did not follow any particular pattern in relation to age. The least mean distance from communities to farms was $2.8 \mathrm{~km}$ for the 30-39 age group and highest mean distance was $5.0 \mathrm{~km}$ for the 40-49 age group. The range for farm distances for male and female participants was 14.5 and $10.0 \mathrm{~km}$, respectively.

Table 1: Participants' mean distances to farms and mean farm sizes per age groups and gender

\begin{tabular}{|c|c|c|c|c|c|c|c|}
\hline & & \multicolumn{3}{|c|}{ Distance To Farm/Km } & \multicolumn{3}{|c|}{ Farm Size/Acres } \\
\hline & & Mean & Std. Dev. & Range & Mean & Std. Dev. & Range \\
\hline \multirow{5}{*}{ Age Group } & $20-29$ & 3.79 & 2.53 & 10.0 & 5.41 & 3.02 & 10.5 \\
\hline & $30-39$ & 2.80 & 1.42 & 5.0 & 6.33 & 3.86 & 10.0 \\
\hline & $40-49$ & 5.00 & 3.34 & 14.0 & 6.03 & 3.14 & 8.0 \\
\hline & $50-59$ & 3.53 & 4.28 & 14.5 & 7.17 & 3.27 & 10.0 \\
\hline & $60+$ & 3.25 & 1.55 & 3.5 & 9.25 & 2.50 & 6.0 \\
\hline \multirow{2}{*}{ Gender } & Male & 3.84 & 2.95 & 14.5 & 7.20 & 3.13 & 10.0 \\
\hline & Female & 3.15 & 2.16 & 10.0 & 4.00 & 2.92 & 10.5 \\
\hline
\end{tabular}


Unlike mean distances to farms by age groups, which did not follow a particular pattern, mean farm sizes of participants generally increased with increasing age. As they get older, farmers have more mouths to feed, there is more available labor to increase farm sizes and they generally control more land resources than those who are younger [27]. Gender also influenced farm sizes and distances to farms. Female participants mean distance to farms and farm sizes are smaller than those of the male participants. While the females' mean farm size was four acres (with a standard deviation of 2.92), for their male counterparts it was 7.2 acres (with a standard deviation of 3.13).

The above findings are related to the socio-cultural and economic circumstances of the study area. These factors influence who has property rights over land and thus control access to cultivate the land. For example, it has been reported that in northern Ghana women do not own land because they do not have the right to sacrifice to the land god, although they would like to have greater access to land [28]. It has also been found that the cost of land is prohibitive to many women in northern Ghana [27].

\subsection{Farm sizes, distances to farms and crop raiding}

Figure 3 shows how farm sizes in acres increase with increasing distance from the communities with more variability at the threekilometer distance from participants' communities.

Farmers move to more pristine areas after exhausting the fertility of agricultural lands closer to the communities. Again, competition for agricultural lands closer means farm sizes around communities will be smaller and therefore those wanting to increase their farm sizes have to move further away. The positive relationship between farm distances and farm sizes in this study attests to the findings made by [29], which reported that farm lands in northern Ghana can sometimes be acquired by clearing virgin lands. The authors mentioned that it is sometimes necessary to travel up to $30 \mathrm{~km}$ before virgin land can be located. This puts the male at an advantageous position of acquiring such a piece of virgin land because he is economically better placed than the female counterpart [27].

The encroachment of farmlands into pristine ecosystems has some negative consequences on wildlife conservation and its associated crop raiding. It has been found that crops which hitherto were not part of the diet of wildlife species have become targets for crop raids [5] and [6]. This has largely been caused by increasing human population leading to the destruction of wildlife habitats. Farmers in this situation kill wildlife in retaliation [4] or to compensate for their loss [2] where the animals are used as food or sold for income [30].

\subsection{Cultivated crops and wildlife crop raids}

Participants were asked to mention the major crop they cultivate in terms of farm size. Maize received most mentions as the major crop cultivated in the two study sites. A total of 67 participants mentioned they cultivate maize as their major crop. Other crops mentioned include groundnut and millet. Table 2 gives details of the major crops cultivated at the two study sites. It was found that no male cultivated groundnut as a major crop and 16 female participants across the two study sites mentioned groundnuts to be their major crop.

Participants were also asked to mention the crop that suffers most raids by wildlife, and maize was mentioned as the one that suffer most raids. Although 67 participants mentioned maize as their major crop, those who mentioned maize as the crop that suffer most raids were 63 . The same happened in the case of groundnut, where 13 mentioned the crop as the one that suffers most raids although 16 participants reported groundnuts as their major crop. Crops like yams and cowpea which were not mentioned as major crops and received mentions as the crop which suffers most raids by three and five participants, respectively.

The majority of the females in this study were found to mainly cultivate groundnut and again this is a land tenure arrangement between

At least one box will not be displayed because it needed more than 4 values or has inadeqaute variability

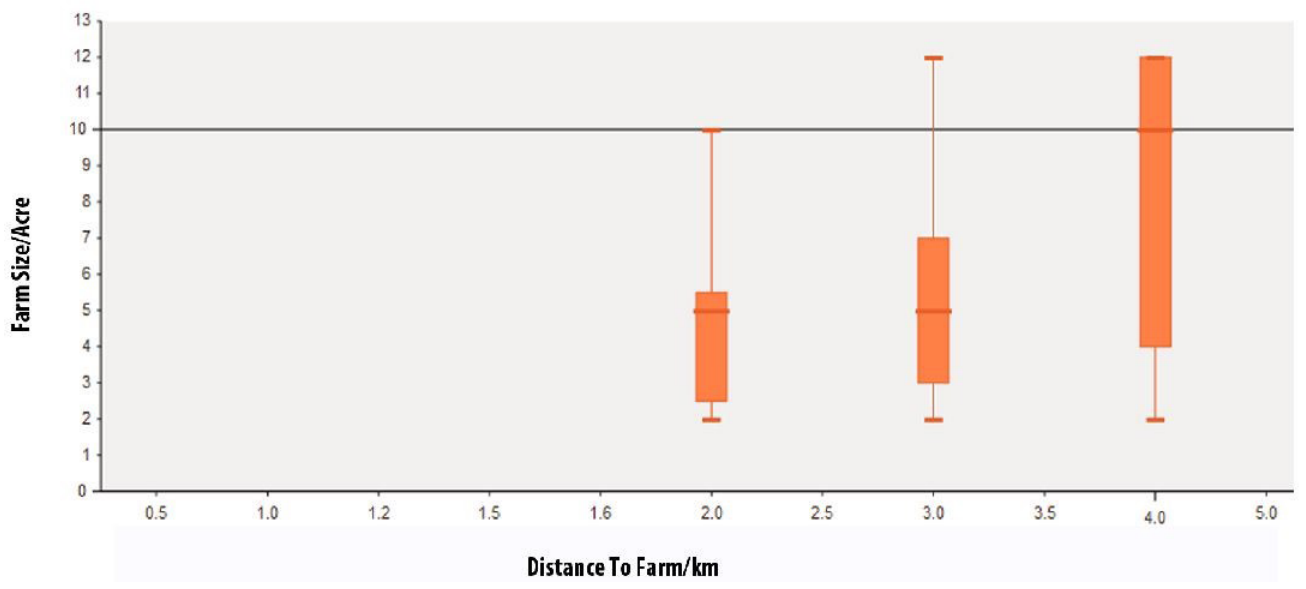

Figure 3: Farm sizes and distance to farms from communities. 
them and their male relatives. Similar findings were made where husbands acquire a piece of land and give a portion to their wives to cultivate essentially food crops [27]. Participants in this study indicated the males allocate marginal lands and crop fields, which have low fertility and cannot support crops like maize, to the females in order to cultivate groundnuts. The leguminous nature of groundnut then improves the fertility of the soil. After two years of cultivating groundnut on a particular piece of land, the male relative will reassume cultivation of crops like maize on the land. Other depleted crop fields will then be allocated to the females for the crop rotation cycle to continue.

\subsubsection{Problem animals and crops raided}

Participants across the two locations mentioned almost the same species as the problem animals that raid their crops (see Table 3 ). There was a statistically significant relation between the participants' responses to species and crops raided in the two locations with the following values: $X^{2}=16.988 ; \mathrm{DoF}=4 ; \mathrm{p}=1.943 \mathrm{e}-3$.

Primate species like the Patas monkey (Erythrocebus patas), Baboon (Papio anubis) and Green Monkey (Cercopithecus aethiops) were mentioned as the species that raided most of the crops apart from yams which was not attributed to the primates. Twenty-eight participants mentioned primates in the GRR compared to 31 from the SKGK. Birds (Quelea spp. and weavers) were the second most mentioned species.

Elephant crop raiding was reported in the SKGK where maize and yam crops were the targets. This is not strange because the SKGK forms part of the annual elephant moving corridor between the adjoining Nazinga Game Ranch in Burkina Faso and Ghana [17]. Participants from the GRR mentioned other species like Warthogs (Phacochoerus africanus) and Crested porcupines (Hystrix cristata) as crop raiding species.

Participants indicated that crop raiding occurs at all stages of the crops' life cycle. This is similar to findings made by [3], where the Lowe Monkey (Cercopithecus campbelli lowei) was mainly mentioned to attack all sorts of crops including food prepared for human consumption in the homes. For example, in this study birds and striped ground squirrels (Euxerus erythropus) were mentioned to raid maize and groundnut seeds planted before and just after germination. Grasscutters (Thryonomys swinderianus) and Crested Porcupines (Hystrix cristata) were mentioned to attack the succulent stems of maize during the sapling stage of the crop. The primates attacked the mature fruits and the seeds of maize, groundnut and the other crops. Elephants also eat the mature tubers of yam and cobs of maize whiles birds again attack mature seeds of maize from the cob. These findings are in line with those reported by [5] and [6]. The concern is the involvement of charismatic species like the primates and elephants which are species that attract most eco-tourists to fund conservation. The worry is that if farmers resort to retaliatory killings [4] tourism receipts will decline [31] and conservation objectives would be jeopardized.

\subsection{Collaborative indicators and crop raids}

Three indicators were used to test whether collaboration between the WD and the community has any impact on farmers' perspectives on

Table 2: Participants' responses to major crops cultivated and crops that suffer most raids

\begin{tabular}{|c|c|c|c|c|c|c|c|c|c|c|}
\hline & & & \multicolumn{3}{|c|}{ Crops Cultivated } & \multicolumn{5}{|c|}{ Crops that Suffer Most Raids } \\
\hline & & & Maize & Groundnut & Millet & Maize & Groundnut & Cowpea & Millet & Yam \\
\hline \multirow{2}{*}{ GRR } & \multirow{2}{*}{ Gender } & Male & 27 & 0 & 1 & 23 & 1 & 2 & 1 & 1 \\
\hline & & Female & 5 & 7 & 0 & 9 & 2 & 1 & 0 & 0 \\
\hline \multirow{2}{*}{ SKGK } & \multirow{2}{*}{ Gender } & Male & 30 & 0 & 2 & 26 & 1 & 2 & 1 & 2 \\
\hline & & Female & 5 & 9 & 0 & 5 & 9 & 0 & 0 & 0 \\
\hline
\end{tabular}

Table 3: Participants' responses of problem animals by location and crops they raid

\begin{tabular}{|c|c|c|c|c|c|c|c|c|}
\hline & & & \multicolumn{6}{|c|}{ Crops that Suffer Most Raids } \\
\hline & & & Maize & $\begin{array}{l}\text { Ground- } \\
\text { nuts }\end{array}$ & Cowpea & Millet & Yam & TOTAL \\
\hline \multirow{4}{*}{ GRR } & \multirow{4}{*}{$\begin{array}{l}\text { Problem } \\
\text { Animals }\end{array}$} & Monkeys (Baboons, Patas \& Green Monkeys) & 22 & 3 & 2 & 1 & 0 & 28 \\
\hline & & Striped Ground Squirrels & 4 & 0 & 1 & 0 & 1 & 6 \\
\hline & & Birds (Quelea Spp.) & 2 & 0 & 0 & 0 & 0 & 2 \\
\hline & & Others (Grasscutters, Porcupines, Warthogs) & 4 & 0 & 0 & 0 & 0 & 4 \\
\hline \multirow{4}{*}{ SKGK } & \multirow{4}{*}{$\begin{array}{l}\text { Problem } \\
\text { Animals }\end{array}$} & Elephants & 4 & 0 & 0 & 0 & 2 & 6 \\
\hline & & Monkeys (Baboons, Patas \& Green Monkeys) & 19 & 9 & 2 & 1 & 0 & 31 \\
\hline & & Striped Ground Squirrels & 1 & 0 & 0 & 0 & 0 & 1 \\
\hline & & Birds (Quelea Spp.) & 7 & 1 & 0 & 0 & 0 & 8 \\
\hline
\end{tabular}


crop raiding at the two study sites. They were 1) methods used by farmers to reduce raiding, 2) institutions to which farmers report raidings, and 3 ) the kind of assistance needed to reduce raiding. The assumption is that an effective collaboration will create a sense of ownership for wildlife resources [3], [4], [32] which will allow community members to share in both their benefits and costs [18], including crop raiding.

\subsubsection{Preventive methods applied by victims}

Four main methods were mentioned in preventing crop raiding in the area. These were trapping, scarecrows, pesticides and manual sound making (shouting or beating of cans or any physical sound making). The study found no significant difference between location and preventive methods $\left(X^{2}=4.307\right.$; $\left.D o F=3, P=0.2302\right)$. Trapping, use of scarecrows and sound making were common to both sites except pesticides usage which was exclusive to the SKGK. It was only the males who mentioned trapping as their methods of preventing crop raids while the females mentioned scarecrows and manual sound making as their preventive methods. Participants mentioned the most effective method among the four is manual sound making. However, the challenge is that one cannot always be at the farm to make noise [31]. Table 4 shows a Chi Square Test of association between location and preventive methods.

The Consolidated Wildlife Laws [16] of Ghana prohibit anyone from hunting wildlife without the appropriate permit from the regulatory agency (WD). The legally prescribed method of hunting is the use of a gun, and it should only be done during the daytime. Trapping, which was found to be the second highest method of preventing crop raiding with 29 recordings after sound making, is prohibited under the law. Trapping and pesticide use are indiscriminate and kill targeted and non-targeted species. Gin traps are the most commonly used traps in the study area and are not only dangerous to wildlife but also human beings who may be unaware of the existence of the trap or the law proscribing its usage. In collaborative arrangements, compliance is an obligation the partners agree to based on the partnership norms and rules [19]. It is therefore expected that trapping would not be one of the preventive methods used by collaborators.

Collaborative initiatives between the WD and the communities begin with conservation education which spell out these regulations [8], [33] before the devolution of authority [8] is given to form a CREMA. The Chi Square statistic of $X^{2}=4.307$ with $p=0.2302$ indicates there is no statistically significant difference between location and preventive methods applied by farmers. This means the WD needs to improve its collaborative activities irrespective of the model (CREMA or CRMCs). Educating and supporting farmers with appropriate preventive methods that are not detrimental to farmers and wildlife will improve conservation outcomes.

\subsubsection{Institutions where crop raiding reports are sent}

A positive collaboration between farmers and the WD is expected to promote the reporting of crop raids to the institution or the CRMCs and the CREMA executives for appropriate redress. This assumption is based on a behavioral paradigm as described by [19], where the impact of social and political interactions on decision-making processes is emphasized. Participants were asked to mention the institution they had reported crop raid incidences to when they suffered raids. Five different institutions were mentioned by participants as the places where crop raiding incidences had been reported.

Although the WD had received 20 reports from farmers within the period, non-reporting is more common with 29 responses. Of the GRR farmers, $47.5 \%$ did not report crop raiding incidences as compared to $21.7 \%$ of SKGK farmers who did not report crop raiding incidences to any institution. It is interesting to note that CREMA and CRMCs executives who live in the communities with the farmers did not receive most reports. However, it can be said there is a better reporting frequency at the CREMA than in the CRMC communities (see Table 5 for details).

A Chi Square Test of association between location and institutions that receive crop raiding reports was conducted and Table 5 above shows the results. The test shows there is a statistically significant difference $\left(X^{2}=14.523\right.$; DoF=5; $\left.P=0.01261\right)$ between location and institutions that received raiding reports. Many reasons impact on human-wildlife conflict and its management [2]. The authors mentioned factors like lack of ecological information, non-involvement of stakeholders in conservation planning, differences between stakeholders on human wildlife conflict definition, disadvantages of negotiations and historical stakes that make conservation threatening. The WD with its historical antecedents and its operational mandate, which hitherto was only under command and control [5], [34], has made it difficult for collaborative partners in local communities to relate as equal partners with the organization. This relationship is in contrast with the definition of collaboration in [34] as a combination of two or

Table 4: Location and preventive methods

\begin{tabular}{|c|c|c|c|c|c|c|c|c|c|c|c|}
\hline \multicolumn{12}{|c|}{ Pearson's Chi Square Test of Association Between "Location" and "Preventive Methods" } \\
\hline & & \multicolumn{10}{|c|}{ Preventive Methods } \\
\hline & & \multicolumn{2}{|c|}{ Traps } & \multicolumn{2}{|c|}{ Scarecrows } & \multicolumn{2}{|c|}{ Pesticides } & \multicolumn{2}{|c|}{ Sound Making } & \multicolumn{2}{|c|}{ TOTAL } \\
\hline & & Obs. & Exp. & Obs. & Exp. & Obs. & Exp. & Obs. & Exp. & Obs. & Exp. \\
\hline \multirow{3}{*}{ Location } & GRR & 13 & 13.5 & 8 & 10.2 & 0 & 0.9 & 19 & 15.3 & 40 & 40 \\
\hline & SKGK & 16 & 15.5 & 14 & 11.8 & 2 & 1.1 & 14 & 17.7 & 46 & 46 \\
\hline & TOTAL & 29 & 29 & 22 & 22 & 2 & 2 & 33 & 33 & 86 & 86 \\
\hline
\end{tabular}

$\left(X^{2}=4.307, \mathrm{DoF}=3, \mathrm{p}=0.2302\right)$ 
more autonomous organizations working together with their resources, structures and norms to offer public good rather than working separately. It is therefore not surprising that the majority of participants (47.5\%) did not report crop raiding to any institutions and the consequence could be retaliatory killing of the animals. How the WD will liaise with the other institutions that receive raiding reports to come up with effective mitigation measures is important in reducing retaliatory killing and increasing farmers trust as equal partners in managing this persistent conflict.

\subsubsection{Assistance required to reduce the impact of crop raiding}

Participants were asked to name the kind of assistance they most require to reduce the impact of crop raiding if the opportunity was given. Four main different types of assistance were requested, including financial support, supply of farm inputs, supply of food or rations, and effective preventive measures. The most requested assistance, mentioned by $45.3 \%$ of participants, was effective preventive methods to reduce crop raiding. Nets, traps and modern forms of scarecrows were some of the suggested methods participants made to reduce the impact of wildlife crop raiding. Table 6 shows the details of participants' responses to assistance needed to reduce the impact of crop raiding. A Chi Square Test conducted between location and assistance needed by victims of crop raids shows there was no statistically significant difference $\left(X^{2}=7.562 ;\right.$ DoF $\left.=3 ; \quad P=0.05599\right)$ between the variables. More participants (13) from GRR requested financial assistance, compared to five (5) from SKGK. Equal numbers of participants (11) from both sites requested farm inputs and only seven from both sites requested for food/rations. [31] had advocated for farmers to receive support when their farms are raided by wildlife. The reason is that farmers sometimes suffer significant damage to their farms which can require replanting an entire field or staying in the farms for long hours to drive away problem animals, implying costs of time and money. It is recommended that the WD should fashion out management regimes that can prevent raids as most participants (45.3\%) requested assistance for preventive measures.

\section{Conclusions}

Issues of gender, crops cultivated and land tenure arrangements were found to influence farm distances and sizes. Females generally have smaller farms and move shorter distances to farms than their male counterparts. The findings suggest that the socio-cultural and economic situation of the study area gives the males an advantage over the females in land tenure security and access to land which also affect the type of crops cultivated by the different genders.

The study findings indicate crop raiding was real and that farmers were likely to fall victim to raids in a cropping season in the study area. Crops like maize, groundnut, cowpea, millet and yam suffer raids from wildlife species like Elephants, Baboons, Patas and Green monkeys. Birds, antelopes and rodents were also mentioned as some other wild animals that raid crops. There was a statistically significant relation between location and participants responses to species that raided their crops and again there was a statistically significant relationship between location and the institutions victims report to. Most of the participants indicated they did not report raiding incidences and this could lead to retaliatory killing. This suggests the type of collaborative model does not impact on wildlife crop raids victims' perspectives.

\section{Table 5: Institutions where crop raiding reports are sent}

\begin{tabular}{|c|c|c|c|c|c|c|c|c|c|c|c|c|c|c|c|}
\hline & \multicolumn{14}{|c|}{ Institutions where Reports are Made } \\
\hline & & \multicolumn{2}{|c|}{$\mathrm{DA}^{1}$} & \multicolumn{2}{|c|}{$\mathrm{NADMO}^{2}$} & \multicolumn{2}{|c|}{ Do not Report } & \multicolumn{2}{|c|}{$\mathrm{WD}^{3}$} & \multicolumn{2}{|c|}{$\mathrm{MoFA}^{4}$} & \multicolumn{2}{|c|}{$\begin{array}{l}\text { CREMA \& } \\
\text { CRMCs }^{5}\end{array}$} & \multicolumn{2}{|c|}{ TOTAL } \\
\hline & & Ob. & Exp. & Ob. & Exp. & Ob. & Exp. & $\mathrm{Ob}$. & Exp. & $\mathrm{Ob}$ & Exp. & Ob. & Exp. & $\mathrm{Ob}$ & Exp. \\
\hline \multirow{3}{*}{$\begin{array}{l}\text { Loca- } \\
\text { tion }\end{array}$} & GRR & 5 & 4.7 & 2 & 4 & 19 & 14 & 6 & 9.3 & 1 & 4 & 7 & 4.7 & 40 & 40 \\
\hline & SKGK & 5 & 5.3 & 7 & 5 & 10 & 16 & 14 & 11 & 7 & 4 & 3 & 5.3 & 46 & 46 \\
\hline & TOTAL & 10 & 10 & 9 & 9 & 29 & 29 & 20 & 20 & 8 & 8 & 10 & 10 & 86 & 86 \\
\hline
\end{tabular}

$\left(X^{2}=14.523, D o F=5, p=0.012\right) 1=$ District Assembly, $2=$ National Disaster Management Organization, $3=$ Wildlife Division 4=Ministry of Agriculture, 5=Community Resources Management Area and Community Resources Management Committees.

Table 6: Participants' requests to reduce the impact of crop raiding

\begin{tabular}{l}
\hline \multicolumn{1}{|c|}{ Pearson's Chi Square Test of Association Between "Location" and "Preventive Methods" } \\
\hline
\end{tabular}

$\left(X^{2}=7.562 ; D o F=3, p=0.05599\right)$ 
The findings also showed there were no statistically significant differences between the other two collaborative indicators (assistance needed and preventive methods) and the study locations. Participants from the two locations did not show differences in their responses to prevention methods as traps were mentioned by male participants to be a major preventive method. This was also reaffirmed by the requests for modern forms of trapping to reduce or mitigate crop raiding which is against the regulatory regimes of the WD.

Human-wildlife conflict is an age old problem for wildlife managers and farmers to deal with. With increasing human population leading to the clearing of pristine ecosystems for expanding agriculture the problem has been exacerbated. The WD has to work with farmers in the spirit of collaboration to manage crop raiding in its protected areas to promote conservation ideals and promote farmers' food security.

\section{References}

[1] M. Baudena, S. C. Dekker, P. M. van Bodegom, B. Cuesta, S. I. Higgins, V. Lehsten, C. H. Reick, M. Rietkerk, S. Scheiter, Z. Yin, M. A. Zavala, and V. Brovkin, "Forests, savannas, and grasslands: bridging the knowledge gap between ecology and Dynamic Global Vegetation Models," Biogeosciences, vol. 12, no. 6, pp. 1833-1848, Mar. 2015. Doi: https://doi.org/10.5194/bg-12-1833-2015

[2] S. M. Redpath, J. Young, A. Evely, W. M. Adams, W. J. Sutherland, A. Whitehouse, A. Amar, R. A. Lambert, J. D. C. Linnell, A. Watt, and R. J. Gutiérrez, "Understanding and managing conservation conflicts," Trends Ecol. Evol., vol. 28, no. 2, pp. 100-109, Feb. 2013. Doi: http://dx.doi.org/10.1016/j.tree.2012.08.021

[3] E. D. Wiafe and F. Arku, "Victims perspectives of Lowe's Monkeys' (Cercopithecus campbelli lowei) crop raiding events in Ghana: A case of Boabeng-Fiema Monkey Sanctuary," J Biodivers. Environ. Sci., vol. 2, no. 2, pp. 1-8, 2012.

[4] G. Enticott, "Techniques of neutralizing wildlife crime in rural England and Wales," BRASS, Cardiff University, Working Paper Series No. 61, 2010.

[5] A. K Monney, B.K. Dakwa, and D.E. Wiafe, "Assessment of crop raiding situation by elephants (Loxodonta africana cyclotis) in farms around Kakum Conservation Area, Ghana," Int. J. Biodivers. Conserv., vol. 2, no. 9, pp. 243-249, Sep. 2010.

[6] S. K. Oppong, E. Danquah and M.K. Sam, "An update on crop-raiding by elephants at Bia Conservation Area, Ghana from 2004-2006," Pachyderm no. 44, pp. 59-64, 2008.

[7] C. Romero, S. Athayde, J.-G. E. Collomb, M. DiGiano, M. Schmink, S. Schramski, and L. Seales, "Conservation and develop. in Latin America and Southern Africa: Setting the stage," Ecol. Soc., vol. 17, no. 2, 2012. Doi: http://dx.doi.org/10.5751/ ES-04863-170217

[8] A. K. Agyare, "Polycentric governance and social-ecological performance of community resource manage. areas in Ghana," Ph.D. dissertation, Dept. Geog., Univ. Victoria, B.C., Canada, 2013.

[9] E. K. Ekpe, C. R. Hinkle, M. F. Quigley, and E. H. Owusu, "Natural resource and biodiversity conservation in Ghana: the use of livelihoods support activities to achieve conservation objectives," Int. J. Biodiversity Science, Ecosystem Services \& Management, vol. 10, no. 4, pp. 253-261, Oct. 2014. Doi: https://doi.org/10.1080/ 21513732.2014.971056

[10] I. B. Jones and K.T. Erdmann, "Community-Based natural resource management in Southern Africa: A decision makers-guide," USAID, Washington, D.C., 2013.

[11] D. Roe, F. Nelson, and C. Sandbrook, Eds., Community management of natural in Africa: Impacts, experiences and future directions, Natural Resource Issues no. 18.
International Institute for Environment and Development, London, UK, 2009.

[12] J. Brooks, K. Waylen, and M. Mulder, "Assessing community-based conservation projects: A systematic review and multilevel analysis of attitudinal, behavioral, ecological, and economic outcomes," Environmental Evidence, vol. 2, no. 1, p. 2, 2013. Doi: https://doi.org/10.1186/2047-2382-2-2

[13] M. T. Buntaine and B. C. Parks, "When do environmentally focused assistance projects achieve their objectives? Evidence from World Bank post-project evaluations," Global Environ. Polit., vol. 13, no. 2, pp. 65-88, May 2013. Doi: https:// doi.org/10.1162/glep a 00167

[14] C. L. Shafer, "Cautionary thoughts on IUCN protected area manage. categories V-Vl," Glob. Ecol. Conserv., vol. 3, pp. 331-348, Jan. 2015. Doi: https://doi. org/10.1016/j.gecco.2014.12.007

[15] G. A. A. Bandoh, "Conservation and natural resource management in the Ankasa Resource Reserve, Ghana," Ph.D. dissertation, Univ. of Waterloo, Ontario, Canada, 2010.

[16] The Wildlife Division, "Consolidated wildlife laws of Ghana," Accra, Ghana, 2002.

[17] The Wildlife Division, "Western wildlife corridor manage. plan," Accra, Ghana, 2017.

[18] M. Lockwood, J. Davidson, A. Curtis, E. Stratford, and R. Griffith, "Governance Principles for Natural Resource Manage.," Soc. Natur. Resour., vol. 23, no. 10, pp. 986-1001, Aug. 2010. Doi: https://doi.org/10.1080/08941920802178214

[19] S. P. Gudergan and G. P. Gudergan, "A dynamic theory of collaboration and decision-making," Proceedings of the 35th Annual Hawaii International Conference on System Sciences. 2002. Doi: https://doi.org/10.1109/hicss.2002.994027

[20] T. M. Koontz, "Collaboration for sustainability? A framework for analyzing government impacts in collaborative-environmental management," Sustainability: Science, Practice and Policy, vol. 2, no. 1, pp. 15-24, Apr. 2006. Doi: https://doi.org/ 10.1080/15487733.2006.11907974

[21] O. Maurin, T. J. Davies, J. E. Burrows, B. H. Daru, K. Yessoufou, A. M. Muasya, M. van der Bank, and W. J. Bond, "Savanna fire and the origins of the 'underground forests' of Africa," New Phytol., vol. 204, no. 1, pp. 201-214, Jul. 2014. Doi: https:// doi.org/10.1111/nph.12936

[22] C. Lungren, "Community resource manage. areas (CREMAs) and collaborative wildlife manage. areas (CWMAs)," Site description and action plan for Wuru-Kayoro collaborative wildlife manage. area, Accra, Wildlife Division Tech. Rep., 2008.

[23] S. K. Oppong and C. Woebong, "Survey of fauna and flora in Gbele resource reserve," Dept. Range and Wildlife Manage., Univ. Develop. Studies, Tamale, Wildlife Division Tech. Rep., 2015.

[24] A. Sloan and B. Bowe, "Phenomenology and hermeneutic phenomenology: the philosophy, the methodologies, and using hermeneutic phenomenology to investigate lecturers' experiences of curriculum design," Qual. Quant., vol. 48, no. 3, pp. 1291-1303, Feb. 2013. Doi: https://doi.org/10.1007/s11135-013-9835-3

[25] M. M Wilcke, "Hermeneutic phenomenology as a research method of social work," Currents: New Scholarship in the Human Services, vol. 1, no. 1, pp. 1-10, 2006.

[26] K. J. Devers, Richard M. Frankel, "Study design in qualitative research-2: Sampling and data collection strategies," Education for Health, vol. 13, no. 2, pp. 263-271, Jul. 2000. Doi: https://doi.org/10.1080/13576280050074543

[27] A. Richardson and R. Gaafar, "Ghana: Land access and tenure security project," Alliance for a Green Revolution in Africa (AGRA), Landesa Rural Develop. Inst., 2016.

[28] M. K. Kaunza-Nu-Dem, B. Tijani, D. Millar, and A. Humphrey, "The complexities of women land ownership in northern Ghana," OALib, vol. 03, no. 08, pp. 1-8, 2016. Doi: https://doi.org/10.4236/oalib.1102789

[29] S. Bambangi, and A. Abubakari, "Ownership and access to land in urban Mamprugu, Northern Ghana," Int. J. Research in Social Sciences, vol 2, no. 2, Jun. 2013.

[30] V. C. O. Eneji, Q. Gubo, F. I. Okpiliya, E. J. Aniah, D. D. Eni and D. Afangide, "Problems of public participation in biodiversity conservation: the Nigerian scenario," Impact 
Assess. Proj. A., vol. 27, no. 4, pp. 301-307, Dec. 2009. Doi: https://doi. org/10.3152/146155109x479431

[31] N. Owusu-Ansah, "Wildlife crop raids: Victims deserve support," Environ. Res. J. vol. 12, no. 1, pp. 1-5, 2018. Doi: https://doi.org/10.3923/erj.2018.1.5

[32] R. A. Asare, A. Kyei, and J. J. Mason, "The community resource management area mechanism: a strategy to manage African forest resources for REDD+," Philos. T. Roy. Soc. B., vol. 368, no. 1625, pp. 20120311-20120311, Jul. 2013. Doi: http:// dx.doi.org/10.1098/rstb.2012.0311

[33] N. Owusu-Ansah, "The application of adaptive management in protected areas," In, Adaptive Management: Elements, application and research, E. D. Wiafe, Ed. New York: Nova Science Publishers, 2017

[34] M. T. Imperial, "Using collaboration as a governance strategy," Admin. Soc., vol. 37, no. 3, pp. 281-320, Jul. 2005. Doi: https://doi.org/10.1177/0095399705276111 